\title{
Management of Spinal Schwannomas in Gabriel Touré Hospital: Review of 11 Cases
}

\author{
Youssouf Sogoba1, Boubacar Sogoba1, Drissa Kanikomo', Seybou Hassane Diallo², \\ Djenè Kourouma', Oumar Coulibaly ${ }^{3}$, Issa Amadou ${ }^{4}$, Moustapha Mangané ${ }^{5}$, \\ Hamidou Almeimounes, Madani Thierno Diop5, Youssoufa Maiga², Broulaye Samaké5, \\ Djibo M. Diango 5
}

\author{
${ }^{1}$ Department of Neurosurgery, Hôpital Gabriel Touré, Bamako, Mali \\ ${ }^{2}$ Department of Neurology, Hôpital Gabriel Touré, Bamako, Mali \\ ${ }^{3}$ Department of Neurosurgery, Hôpital du Mali, Bamako, Mali \\ ${ }^{4}$ Department of Pediatric Surgery, Hôpital Gabriel Touré, Bamako, Mali \\ ${ }^{5}$ Department of Anesthesiology and ICU, Hôpital Gabriel Touré, Bamako, Mali \\ Email: sogobayoussouf@yahoo.fr
}

How to cite this paper: Sogoba, Y., Sogoba, B., Kanikomo, D., Diallo, S.H., Kourouma, D., Coulibaly, O., Amadou, I., Mangané, M., Almeimoune, H., Diop, M.T., Maiga, Y., Samaké, B. and Diango, D.M. (2018) Management of Spinal Schwannomas in Gabriel Touré Hospital: Review of 11 Cases. Surgical Science, 9, 256-261.

https://doi.org/10.4236/ss.2018.98031

Received: July 27, 2018

Accepted: August 19, 2018

Published: August 22, 2018

Copyright (c) 2018 by authors and Scientific Research Publishing Inc. This work is licensed under the Creative Commons Attribution International License (CC BY 4.0).

http://creativecommons.org/licenses/by/4.0/

\section{(c) () Open Access}

\begin{abstract}
Background: Spinal schwannomas are common tumors of spinal neoplasm and account for about $25 \%$ of intradural spinal cord tumors in adults. They are generally benign and slow-growing. Advanced in radiologic and surgical techniques have brought about better surgical results. The goal of surgical treatment must be total resection if possible. In this report, the authors present the incidence, clinical presentation, localization, and results of surgically treated spinal schwannomas. The results of a literature review are also presented. Methods: Eleven consecutive patients with histologically confirmed spinal schwannomas were treated from January 2013 to December 2016 in the neurosurgical department of Gabriel Touré Hospital, Bamako, Mali. Neuroradiological diagnosis was made, CT scan in 7 patients, and MRI in 4 patients. All patients were operated on via the posterior approach. All cases were surgically excised, and they were confirmed to be schwannomas by pathologists. The patients were followed for 6 to 38 months (mean 28 months). Functional outcome was assessed using the motor grade and sensory change. Results: There were 11 patients with 7 (63.6\%) males and 4 (36.4\%) females. The mean age was 40.3 years (range 23 - 62 years). The most common symptom at the time of diagnosis was radicular pain in $9(81.8 \%)$ patients followed by motor weakness in $8(72.7 \%)$ patients. The most frequent site of spinal schwannomas was the thoracic region in $5(45.5 \%)$ patients. During surgery, Gross-total resection was achieved in 8 patients $(72.7 \%)$ and subtotal removal in $3(27.3 \%)$ patients. Histological findings were benign schwannoma in all
\end{abstract}


cases. Postoperative complications developed in two patients, including one with cerebrospinal fluid leakage and other one with wound infection. In the short-term follow-up period, most of the patients (90.9\%) appeared to be improved in comparison with their preoperative neurological status. There was no operative mortality. Conclusion: In this study, the clinical manifestations and surgical results of 11 cases of spinal schwannoma have been reviewed. Early diagnosis and appropriate treatment are essential for good outcome.

\section{Keywords}

Spinal Schwannoma, Spine Surgery, Recurrence

\section{Introduction}

Intraspinal tumors are common neurogenic tumors, accounting for approximately $15 \%$ of central nervous system tumors [1]. Spinal schwannomas account for about 25\% of intradural spinal cord tumors in adults [2] [3] [4] [5]. The incidence of spinal schwannomas varies between $0.3-0.4$ cases/100,000 persons per year [5]. It is common benign tumor in spinal canal [6] [7] and due to the slow tumor growth, hidden onset and no specific symptoms and signs, its early diagnosis is more difficult, and some patients are not treated until they are paralyzed. The total excision of the lesion, which is the generally reachable goal of surgery, allows for good results in the cases in which the preoperative clinical findings are not particularly severe. In this study, the authors report 11 cases of spinal schwannomas who were admitted to the Gabriel Touré Hospital from January 2013 to December 2016. The aim of this study was to analyze clinical characteristics and outcome after surgical treatment of patients with spinal schwannomas.

\section{Methods}

Eleven consecutive patients with histologically confirmed spinal schwannomas were treated from January 2013 to December 2016 in the neurosurgical department of Gabriel Touré Hospital, Bamako, Mali. Neuroradiological diagnosis was made, CT scan in 7 patients (Figure 1), and MRI in 4 patients (Figure 2). All patients were operated on via the posterior approach. All cases were surgically excised, and they were confirmed to be schwannomas by pathologists. The patients were followed for 6 to 38 months (mean 28 months). Functional outcome was assessed using the motor grade and sensory change.

\section{Results}

There were 11 patients with $7(63.6 \%)$ males and $4(36.4 \%)$ females. The mean age was 40.3 years (range 23 - 62 years). The courses of disease ranged from 10 to 68 months (mean 28 months). The most common symptom at the time of 


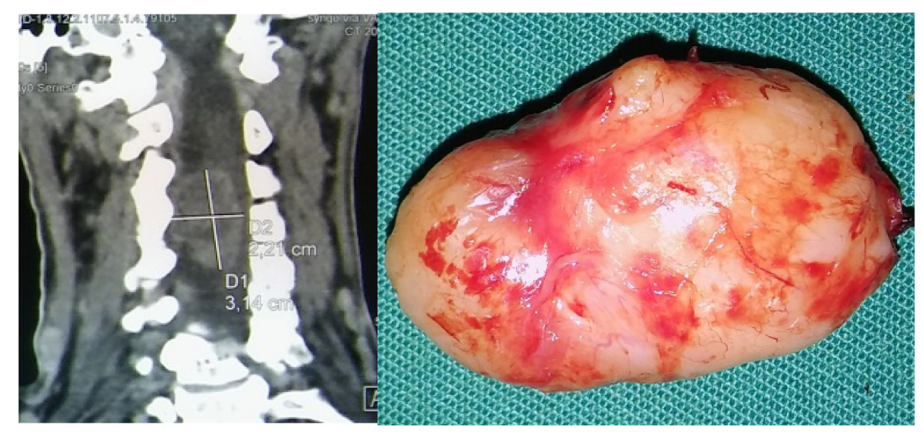

(a)

(b)

Figure 1. Preoperative CT scan (a) and Gross-total resection (b) of cervical schwannoma.

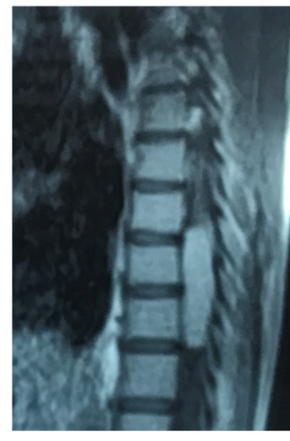

(a)

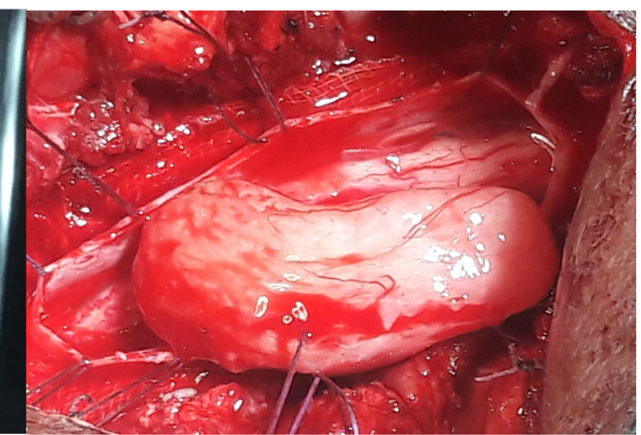

(b)

Figure 2. Preoperative MRI (a) and operative view with Gross-total resection of thoracic schwannoma (b).

diagnosis was radicular pain in $9(81.8 \%)$ patients followed by motor weakness in $8(72.7 \%)$ patients (Table 1$)$. The most frequent site of spinal schwannomas was the thoracic region in $5(45.5 \%)$ patients. Three $(27.3 \%)$ cases were located in cervical area, and other $3(27.5 \%)$ in lumbar region. All of the tumors were removed surgically via laminectomy through posterior approach. Gross-total resection was achieved in 8 (72.7\%) patients (Figure 1 and Figure 2) and subtotal removal in $3(27.3 \%)$ patients. Histological findings were benign schwannoma in all cases. The patients were followed for 6 to 38 months (mean 28 months). In the follow-up period, most of the patients (90.9\%) appeared to be improved in comparison with their preoperative neurological status (Table 2). There was no operative complication or mortality and no recurrence in the short-term follow-up.

\section{Discussion}

Spinal schwannomas are slow-growing benign tumors with a capsule that originates in the myelin sheath. They account for about $25 \%$ of primary intradural spinal cord tumors in adults. Several authors had reported that there is equal incidence in males and females [2] [3] [4] [5] [8]. In our study, the prevalence was higher in males with $63.6 \%$. The incidence of spinal schwannoma varies with the 
Table 1. Clinical Characteristics of spinal schwannoma in 11 patients.

\begin{tabular}{cc}
\hline Symptoms & $\mathrm{N}(\%)$ \\
\hline Radicular pain & $9(81.8)$ \\
Motor weakness & $8(72.7)$ \\
Sensory loss & $5(45.4)$ \\
Back pain & $5(45.4)$ \\
Sphincter disturbances & $2(18.2)$ \\
\hline
\end{tabular}

Table 2. Post-operative outcome of spinal schwannoma in 11 patients.

\begin{tabular}{cc}
\hline Outcome & $\mathrm{N}(\%)$ \\
\hline Recovered & $4(36.4)$ \\
Improved & $6(54.5)$ \\
Stable & $1(9.1)$ \\
Worsened & $0(0)$ \\
Dead & $0(0)$ \\
\hline
\end{tabular}

age of affected patients who are between the 4th and the 5th decade [5] [9]. The mean age was 40.3 years in this report. The initial symptoms are varied in accordance with the level of the tumor. The main symptoms and signs are pain, paresthesia and sphincter disturbances. At the beginning the root pain is attributed to the disturbance of nerve conductivity because of the direct or indirect irritation of nerve root or root compression by the tumor [2] [4] [10]. Motor weakness occurs when compression increases to spinal cord, spinal tracts get damaged and myelopathy develops [11] [12]. Our study confirms that pain is the most common presenting symptom in patients with spinal schwannomas [5] [9] [13]. Early diagnosis is critical because the long-term spinal cord compression may lead to permanent loss of function. The course of disease in this study was 10 - 68 months (mean 28 months) leading to weakness in 8 (72.7\%) patients. Sphincter disturbances were found in $2(18.2 \%)$ patients in our study while some authors have reported a rate of 5\% [10]. Spinal schwannomas can occur at any level of the spinal column [5] [8] [9] [13] [14].

There is some discrepancy in the literature regarding the occurrence of spinal schwannomas along the longitudinal axis of the spine [8] [13]. These inconsistencies may reflect ethnic differences in the incidence of schwannomas [8] [14]. In our study, the higher incidence was seen in the thoracic region in $5(45.5 \%)$ patients. In the literature, $70 \%$ to $80 \%$ of spinal schwannomas are reported to be intradural in location [8] [15]. Our study also confirms that fact. There was no extradural-intradural, extradural or intramedullary schwannomas in our study. The goal of the surgical treatment in patients with spinal schwannomas is total tumor resection while preserving associated neurovascular structures and preventing neurological deterioration. There may be two obstacles to total resection: one is adhesion to the spinal cord; the other is critical structures attached to extradural components outside the spinal canal in the cervical region, such as 
the vertebral artery. In our study Gross-total resection was achieved in 8 (72.7\%) patients. The authors of several studies have shown that schwannoma is associated with a higher rate of tumor recurrence [2] [5] [9] [13]. There was no recurrence in this study. However, the relatively short followup period may explain these findings, because spinal schwannomas can recur many years after their initial resection. Klekamp J and Samii M [9] found that the recurrence rate was $10.7 \%$ after 5 years and $28.2 \%$ after 10 and 15 years. In our study, none of these patients required postoperative fixation. Postoperative instability can occur after resection removal of facet joints and require surgical stabilization [16] [17] [18]. One patient suffered from cerebrospinal fluid leakage after operation. The outcome of spinal schwannoma correlates to preoperative neurological condition of patient [12] [19]. In the follow-up period, most of our patients (90.9\%) appeared to be improved in comparison with their preoperative neurological status.

\section{Conclusion}

In this study, the clinical manifestations and surgical results of 11 cases of spinal schwannoma have been reviewed. Early diagnosis and appropriate treatment are essential for good outcome.

\section{Conflicts of Interest}

The authors declare no conflicts of interest regarding the publication of this paper.

\section{References}

[1] Weber, C., Gulati, S., Jakola, A.S., Habiba, S., Nygaard, Ø.P., Johannesen, T.B. and Solheim, O. (2014) Incidence Rates and Surgery of Primary Intraspinal Tumors in the Era of Modern Neuroimaging: A National Population-Based Study. Spine, 39, E967-E973. https://doi.org/10.1097/BRS.0000000000000412

[2] Celli, P., Trillo, G. and Ferrante, L. (2005) Spinal Extradural Schwannoma. Journal of Neurosurgery Spine, 2, 447-456. https://doi.org/10.3171/spi.2005.2.4.0447

[3] De Verdelhan, O., Haegelen, C., Carsin-Nicol, B., Riffaud, L., Amlashi, S.F., Brassier, G., et al. (2005) MR Imaging Features of Spinal Schwannomas and Meningiomas. Journal of Neuroradiology, 32, 42-49. https://doi.org/10.1016/S0150-9861(05)83021-4

[4] Dorsi, M.J. and Belzberg, A.J. (2004) Paraspinal Nerve Sheath Tumors. Neurosurgery Clinics of North America, 15, 217-222. https://doi.org/10.1016/j.nec.2004.02.007

[5] Seppala, M.T., Haltia, M.J., Sankila, R.J., Jaaskelainen, J.E. and Heiskanen, O. (1995) Long-Term Outcome after Removal of Spinal Schwannoma: A Clinicopathological Study of 187 Cases. Journal of Neuroradiology, 83, 621-626.

[6] Pan, Z., Yang, G., He, H., Zhao, G., Yuan, T., Li, Y., Shi, W., Gao, P., Dong, L. and Li, Y. (2016) Concurrent Radiotherapy and Intrathecal Methotrexate for Treating Leptomeningeal Metastasis from Solid Tumors with Adverse Prognostic Factors: A Prospective and Single-Arm Study. International Journal of Cancer, 139, 1864-1872. https://doi.org/10.1002/ijc.30214 
[7] Sowash, M., Barzilai O, Kahn, S., McLaughlin, L., Boland, P., Bilsky, M.H. and Laufer, I. (2017) Clinical Outcomes Following Resection of Giant Spinal Schwannomas: A Case Series of 32 Patients. Journal of Neurosurgery Spine, 26, 494-500. https://doi.org/10.3171/2016.9.SPINE16778

[8] Jinnai, T. and Koyama, T. (2005) Clinical Characteristics of Spinal Nerve Sheath Tumors. Analysis of 149 Cases. Neurosurgery, 56, 510-515. https://doi.org/10.1227/01.NEU.0000153752.59565.BB

[9] Klekamp, J. and Samii, M. (1998) Surgery of Spinal Nerve Sheath Tumors with Special Reference to Neurofibromatosis. Neurosurgery, 42, 279-290. https://doi.org/10.1097/00006123-199802000-00042

[10] Safaee, M.M., Lyon, R., Barbaro, N.M., Chou, D., Mummaneni, P.V., Weinstein, P.R., Chin, C.T., Tihan, T. and Ames, C.P. (2017) Neurological Outcomes and Surgical Complications in 221 Spinal Nerve Sheath Tumors. Journal of Neurosurgery Spine, 26, 103-111. https://doi.org/10.3171/2016.5.SPINE15974

[11] Hori, T., Takakura, K. and Sano, K. (1984) Spinal Neurinomas-Clinical Analysis of 45 Surgical cases. Neurologia Medico-Chirurgica (Tokyo), 24, 471-477. https://doi.org/10.2176/nmc.24.471

[12] Subaciute, J. (2002) Early Diagnosis of Spinal Cord Schwannoma: The Significance of the Pain Syndrome. Medicina (Kaunas), 38, 1086-1088.

[13] Conti, P., Pansini, G., Mouchaty, H., Capuano, C. and Conti, R. (2004) Spinal Neurinomas: Retrospective Analysis and Long-Term Outcome of 179 Consecutively Operated Cases and Review of the Literature. Surgical Neurology, 61, 34-44. https://doi.org/10.1016/S0090-3019(03)00537-8

[14] Seppälä, M.T., Haltia, M.J., Sankila, R.J., Jääskeläinen, J.E. and Heiskanen, O. (1995) Long-Term Outcome after Removal of Spinal Neurofibroma. Journal of Neuroradiology, 82, 572-577. https://doi.org/10.3171/jns.1995.82.4.0572

[15] McCormick, P.C., Post, K.D. and Stein, B.M. (1990) Intraduralextramedullary Tumors in Adults. Neurosurgery Clinics of North America, 1, 591-608. https://doi.org/10.1016/S1042-3680(18)30792-7

[16] Goel, A. (1996) Posterior Inter-Body Fusion after Spinal Tumor Resection. British Journal of Neurosurgery, 10, 201-203. https://doi.org/10.1080/02688699650040386

[17] Mazel, C., Hoffmann, E., Antonietti, P., Grunenwald, D., Henry, M. and Williams, J. (2004) Posterior Cervicothoracic Instrumentation in Spine Tumors. Spine, 29, 1246-1253. https://doi.org/10.1097/00007632-200406010-00015

[18] Lonstein, J.E. (1977) Post-Laminectomy Kyphosis. Clinical Orthopaedics and Related Research, No. 128, 93-100. https://doi.org/10.1097/00003086-197710000-00012

[19] Mathew, P. and Todd, N.V. (1993) Intraduralconus and Caudaequinatumours: A Retrospective Review of Presentation, Diagnosis and Early Outcome. Journal of Neurology, Neurosurgery, and Psychiatry, 56, 69-74.

https://doi.org/10.1136/jnnp.56.1.69 